\title{
Research on the Development Mode of Old-age Real Estate for Small and Medium-sized Enterprises in China
}

\author{
Yingjun Duan \\ School of Politics and Public Administration, Shanxi University, Taiyuan, P. R. China \\ Email address: \\ dyjdream@163.com \\ To cite this article: \\ Yingjun Duan. Research on the Development Mode of Old-age Real Estate for Small and Medium-sized Enterprises in China. Journal of \\ Business and Economic Development. Vol. 4, No. 3, 2019, pp. 107-112. doi: 10.11648/j.jbed.20190403.15
}

Received: August 7, 2019; Accepted: August 30, 2019; Published: September 20, 2019

\begin{abstract}
With the deepening of the population aging and the growth of the economy in China, the demand for improving the lives of the elderly groups is increasing, and the prospects of the old-age industry, especially the real estate market for the old-age, are bright. Small and medium-sized enterprises (SMEs) play an important role in promoting the development of the old-age real estate. The development of the old-age real estate for SMEs is not only conducive to the healthy development of the old-age real estate market, but also conducive to the middle and low-income elderly to enjoy high-quality and convenient old-age services. The method adopted in this paper is mainly to compare the modes that SMEs can adopt in the three links of development, financing and operation of the old-age real estate, to calculate the costs and benefits of various modes, and to analyze their advantages and disadvantages. The types of enterprises suitable for various modes are also discussed. The conclusion of this paper is that for different links, SMEs should adopt different modes in the process of developing old-age real estate. In terms of development mode, SMEs should choose to cooperate with service agencies because SMEs have weak capital strength and risk tolerance, narrow financing channels and less market resources. In terms of financing mode, SMEs should choose government-enterprise cooperation because it can reduce the development cost, especially the cost of land, also can obtain policy support and administrative approval convenience. In addition, this mode can well reflect the profitability and welfare characteristics of the old-age real estate and can achieve social spillover benefits. In terms of operation mode, SMEs should choose only construction but not operation so as to avoid the risks brought by the latter operation.
\end{abstract}

Keywords: SMEs, Old-age Real Estate, Business Mode, BOT, PPP

\section{Introduction}

Old-age real estate is a kind of old-age residential product which is suitable for the elderly to live in, conforms to the psychological and physiological characteristics of the elderly and can meet the needs of social activities of the elderly, and provides good infrastructure for the health of the elderly. At present, China has entered the aging society and become the country with the largest elderly population in the world. At the same time, the rapid development of China's economy and the tremendous improvement of people's living standards provide a broad space for the development of old-age real estate. Old-age real estate, which integrates the living and recuperation services of the elderly, has gradually become the focus of small and medium-sized enterprises (SMEs) investment [1].

\section{Feasibility on Developing Old-age Real Estate for SMEs in China}

Commercial real estate development is faced with economic risk, legal risk and market risk, etc. SMEs are at a disadvantage in the development, while the old-age real estate can avoid risks to a certain extent [2].

\subsection{The Government Is Facing Enormous Pressure of Population Aging}

China now has a large elderly population and the accelerated growth of aging, so the government have to bear the tremendous pressure of the aging society. Because of the implementation of the previous one-child policy, there are many one-child families who are facing the double pressure of 
caring for the elderly and living. While the government undertakes the expenditure of pension, medical insurance and other living items, it also undertakes the expenditure of welfare items such as old-age service facilities. If the middle and low-end old-age real estate is developed by SMEs, it can not only alleviate the financial pressure of the government, increase government revenue, but also enable these elderly people to enjoy professional old-age services and medical services so as to reduce the probability of disease. Besides, it also provides an investment channel for the elderly. [3]

\subsection{The Development Potential of Middle and Low-end Old-age Real Estate Is Huge}

At present, the main objects of China's old-age real estate are high-income elderly families.. Enterprises are keen to develop high-end old-age market in order to obtain sufficient investment returns. For example, in the TaiKang Home old-age community developed by TaiKang life insurance company in Beijing, After paying the insurance fee of 2 million yuan, people can not only get the qualification to live in the old-age community, but also Access to life-long medical insurance, life-long serious illness insurance, high-rated life insurance and high-level accident insurance [4]. Although consumers can enjoy abundant old-age and medical insurance products, they have to cross the threshold of 2 million yuan and continue to pay rental fees in the later period. This is a long-term and heavy burden for the middle and low-income elderly groups. So if the basic quality of life for the aged is guaranteed, SMEs can develop old-age real estate projects for the middle and low-income elderly, which undoubtedly has great attraction for them, and can reduce the burden of the government to a certain extent.

\subsection{Policy Support}

Chinese government's support for SMEs' development of old-age real estate mainly comes from two aspects. One aspect is government subsidies. Government subsidies to SMEs mainly come from financial support, such as price preferences for land purchase and tax relief preferences for later operation. Government subsidies can enable SMEs to obtain profits, on the other hand, it can improve the overall level of low-end old-age real estate, obtain good social benefits and spillover effects. Second aspect is faster certification and administrative processes [5]. SMEs can get the old-age real estate franchise from the government more quickly. It is convenient for SMEs to implement the design and construction of projects quickly, and reduce the pressure and obstacles they encounter in administrative management [6].

\section{Comparison of Business Modes of Old-age Real Estate}

Old-age real estate business modes can be divided into development model, financing model and operation model, each model can be subdivided into many types, which have their own advantages and disadvantages.

\subsection{Comparison of Development Modes}

Development modes refer to the way real estate companies achieve the design, investment, planning and landing of the project. Different development modes also correspond to different investment risks, investment returns, the speed of cost recovery and enterprise assets and liabilities. Development modes of the old-age real estate, which require higher capital strength, market positioning and self-resources of enterprises, are more complex than those of the general commercial real estate development [7]. There are three main commercial development modes of old-age real estate in China.

\subsubsection{Cooperation with Communities}

This development mode refers to the cooperation between the development enterprises and the communities to build the old-age real estate. On the basis of the communities, the existing resources of the community could be fully utilized. This model can be divided into three types According to the demand for funds and the difficulty of development.

The first is building the large-scale old-age community. The community could be built into a comprehensive professional place for the aged by the cooperation of enterprises and community. The market is positioned for all the elderly consumer groups. All resources in the community are also used for the old-age service to provide high-quality old-age life for the elderly.

The second is building the old-age unit in the community. Enterprises can unite communities and transform some of them into old-age housing, and build old-age service supporting facilities in the community at the same time. This type can be targeted at a variety of consumers, such as young people or the elderly.

The third is building a shared service institution for the elderly. This type enables enterprises to establish a unified and shared service organization for the elderly among adjacent communities, where the elderly in the neighboring communities can consume services or goods they need. It does not involve the development of old-age housing, but focuses on the health, medical and cultural needs of the elderly, so it is not a real commercial old-age real estate project in the traditional sense. However, this type faces the smallest risk, the least investment, the fastest cost recovery and the most stable sustainable income.

\subsubsection{Cooperation with Service Agencies}

This development mode refers to enterprises providing old-age housing, while the relevant old-age service institutions provide a series of old-age services, including medical care, health sports, cultural entertainment, catering and so on. This mode is essentially based on old-age real estate as the core, by deep cultivation of the old-age industry chain, to achieve the coexistence of multiple profit channels. This cooperation mode pays more attention to the user experience of the elderly customers, facilitates the management of enterprises, makes better use of funds and integrates social resources. 
This mode includes two types: one is the co-construction of enterprises and universities, that is, colleges and universities provide educational platforms and other cultural services for the elderly living nearby. Generally this type is not expected by the market. First, it is difficult to find a high-level university with willingness to cooperate. Second, services are limited to cultural and educational aspects, not in line with the multi-level needs of the elderly. The other is to introduce professional medical and nursing institutions, health centers and catering institutions into the community, and enterprises can obtain rent and management fees from these service institutions to achieve multi-channel profits.

\subsubsection{Cooperate with Scenic Spots}

Enterprises can also cooperate with some large-scale tourist scenic spots in the development of old-age real estate. These scenic spots generally have good natural conditions, clean air, beautiful scenery [8]. They are very suitable for the elderly, especially the elderly with certain diseases, to enjoy retirement life. There are two types of this mode. One is to cooperate with sanatoriums in scenic spots, which usually have a perfect service system for the elderly, so enterprises only need to rent to complete the development of old-age real estate projects. The other is that, under the scenic spot franchise, enterprises themselves will build some similar sanatorium housing, while providing housing and services, which can also create a suitable living environment for the elderly and make the enterprise more competitive in the old-age real estate market.

The above three development modes have their own advantages and disadvantages. First, from the perspective of investment cost, the cost of cooperation with scenic spots is higher than the other two. Because the cost of land in scenic spots is higher than that in suburban areas, enterprises have to pay high rent or construction costs, and invest a certain amount of money in service facilities, whether they rent or build the old-age housing around scenic spots. However, if enterprises choose to co-construct with community or service organizations, they can transfer the cost of housing construction or service facilities to the other side of the cooperation, and most enterprises will choose to construct in the suburbs with lower land cost, which is conducive to alleviating the pressure of assets and liabilities in the early stage of development. Secondly, from the perspective of cost recovery period and income sustainability, modes of Co-construction with service agencies and cooperation with scenic spots have shorter recovery period. The cost of enterprises development of old-age housing can be quickly compensated by one-time leasing. Compared with the latter, the former can also collect rent or management fees from the imported professional service agencies at the later stage of operation, which is also a sustainable and stable way to obtain profits. The main profitable way of Co-construction with the community is to charge various service fees in the later stage of operation, in which the cost recovery period is too long and there are certain risks. Thirdly, from the perspective of service professionalism, the way of Co-construction with service institutions can give full play to the professionalism of medical and nursing institutions, entertainment organizations and elderly health organizations. Enterprises can also focus on the design and construction of special housing suitable for the elderly. The other two ways can not better reflect the professional depth of each link in the elderly industry chain, but only realize the expansion of service breadth [9].

\subsection{Comparison of Financing Modes}

Financing mode is the core link of enterprise development projects. Enterprises need to develop financing channels, obtain the planned funds needed in project evaluation in some way, make relevant investments and ultimately obtain the expected income and repay the liabilities according to the contract. Different financing modes correspond to different debt pressures, contractual relationships and income from self-retained investment, and also reflect different levels of economic and legal risks [10].

\subsubsection{Self-financing Mode}

This financing mode refers to the development of old-age real estate projects by enterprises using all their own funds or expanding financing through their own channels. It is generally applicable to large-scale enterprises with relatively strong financial strength.

There are many advantages to self-financing. Enterprises of self-financing are easy to operate and do not involve disputes of economic interests. Enterprises' economic decision-making and fund management are all under their own responsibility. It is conducive to the implementation of the plan in full accordance with the expected objectives and plans of enterprises, and enterprises generally enjoy all investment returns. However, the disadvantage of the mode is too large investment risk to be dispersed.

\subsubsection{Social Participation Financing Mode}

The development of old-age real estate projects has the characteristics of large investment volume, large investment risk and long investment return period. Enterprises with weak financial strength are not enough to support the whole project construction. Although large enterprises have sufficient funds, they generally choose multi-stakeholders to co-invest because of the difficulty in dispersing the risks of self-financing mode. There are two types of social participation financing modes.

The first is business cooperation mode. Real estate developers, medical service enterprises, cultural and entertainment enterprises and catering enterprises jointly participate in the construction under the restriction of the contract, forming a financing mode with real estate enterprises as the main body of investment and other enterprises' cooperative investment. Every main part is just a business partnership, has independent financial rights to each other, and does not involve the accumulation and use of funds [11]. The advantage of this mode is that it can avoid disputes of economic interests. Institutions and developers are responsible for their own profits and losses. It is conducive to providing high-quality professional services, but this model will reduce 
the investment returns of real estate developers.

The second is real estate private equity investment fund. This financial model means that real estate developers raise certain funds from social capital through private fund management companies. Investment companies are responsible for fund management and investment in real estate projects. When the project is completed, real estate developers can distribute earnings to investors by listing, repurchasing equity, selling real estate, and so on, and ensure the reasonable withdrawal of private equity funds. The CIRC has approved the establishment of private equity funds to support the development of SMEs. Because of the high threshold and the lock-in period of withdrawal, this financing mode makes the fund raised large and stable. Besides, the professionalism of fund management companies ensures the standardization of investment and can strongly support real estate developers in developing old-age real estate. The disadvantage of this mode is that it has high market risk. The risk of PE in real estate mainly comes from the operation risk and policy risk caused by the high uncertainty of the market. At present, the history of private equity fund in China is not long, and its withdrawal mechanism needs to be improved constantly.

\subsubsection{Government-Enterprise Cooperation Mode}

This model can be divided into two types: BOT and PPP.

The first is BOT (Build-Operate-Transfer). This mode is generally applied to the construction of public welfare projects. It means that the government and enterprises sign a licensing agreement in the early stage. The government transfers the responsibility of project design, financing, construction, operation and management to enterprises, and generally does not provide money. Enterprises can have a fixed period of operation rights, and rent and sell projects to obtain investment returns. After the expiration of the period, enterprises should transfer the project to the government management free of charge. Compared with the traditional mode, BOT financing mode has higher efficiency in design, construction and operation, and users can also obtain higher quality of service. This financing mode enables real estate developers to acquire land at a lower cost and concentrate funds on the construction of old-age housing and infrastructure to meet the needs of the old-age market. Land cost accounts for a large proportion of the total cost of old-age real estate development, which is equivalent to reducing the financing needed by old-age real estate enterprises and making enterprises enter the old-age real estate market at a lower cost. The old-age real estate developed by BOT mode also has welfare. Under the supervision and management of the government, it can meet the needs of the old-age service for the middle and low-income elderly [12].

The second is the PPP model. This model refers to the partnership between the government and private organizations in order to provide some public goods and services, based on the concession agreement, and through the signing of contracts to clarify the rights and obligations of both parties, so as to ensure the smooth completion of cooperation. Ultimately, the two sides will achieve more favorable results than expected by acting alone. Similar to BOT, the partners of PPP are also government and enterprise, but in PPP mode, government participation is higher, and the project does not need to be transferred to the government in the later stage. In BOT mode, the responsibility and risk of enterprises are much greater than that of the government, and the operation right has a fixed period. In the PPP model, the government can give full play to its policy advantages to make it more convenient for private organizations to develop old-age real estate and get financial support from the government, while enterprises can make full use of idle social funds to invest in old-age real estate projects, and integrate market resources to improve the efficiency and quality of project construction. This mode is conducive to the sharing of interests and risks between the two sides, alleviating the financial pressure of the government to carry out social welfare undertakings, increasing the mobility of social capital. Enterprises can also operate old-age real estate under the government concession agreement, and obtain sustained and stable investment returns in the later period of operation [13].

Financing model is the most important link in the development of old-age real estate. The advantages and disadvantages of each model can be analyzed from the following perspectives. The first is the level of risk. The risk of self-financing model is the biggest and all investment risks are basically borne by enterprises themselves. The other two belong to the risk-sharing with partners, but the proportion of risk-sharing is different. The second is the difficulty of financing. The financing difficulty of social participation mode is the greatest, because enterprises need to cooperate with many investors, including fund management companies, and the economic interests involved are complex. Especially the PE mode of real estate needs to evaluate the profitability of investment. Due to the support of the government, the financing difficulty of the government-enterprise cooperation mode is relatively small. The third is welfare. In the mode of government-enterprise cooperation, the government supports enterprises to manage old-age real estate in order to achieve the goal of social welfare, meet the needs of the middle and low-income elderly, and maximize social benefits. In contrast, the profitability of the other two modes is more obvious [14].

\subsection{Comparison of Operational Modes}

The operation mode of old-age real estate refers to the process of project operation and project profitability in some way after the completion of the development of real estate projects, such as sales model, community management model and so on.

\subsubsection{Combining Construction with Operation}

This model is that enterprises are not only responsible for the construction of old-age real estate in the early stage, but also responsible for the operation of old-age community and the management of service facilities in the later stage. Taking the "QinHeYuan" old-age community in Shanghai as an example, the old people who buy the bearer card enjoy the permanent right to use the house, and can realize the inheritance and transfer of 
the right through the contract; the old people who buy the registered card only enjoy the right to use the house for life, but cannot realize the inheritance and transfer of the right. The mode can not only bring back the development cost, but also win the value-added space for property rights. This model enables enterprises to extend the old-age industry chain, continuously and steadily obtain all links of profitable income, to maximize economic benefits, but enterprises need to have strong financial strength and risk tolerance.

\subsubsection{Construction but Not Operation}

Enterprises are only responsible for the landing of old-age real estate projects, while community and service facilities are operated by introducing professional property management companies and service providers, which are self-managed and responsible for their own profits and losses. Enterprises can only collect rents and other fees regularly from them. This mode is generally suitable for SMEs. Generally, through the combination of rent and sale, they can not only realize the quick return of cost by selling part of the houses, reduce the risk brought by the long return period of investment, but also obtain value-added benefits by renting houses. The disadvantage of this mode is that the industry chain is too short to enjoy the value-added benefits of the elderly services [15]. The above two modes of operation mainly focus on the difference of value-added benefits brought about by different length of industrial chain and the difference of risks brought by different length of return on investment. The first model can be applied to large enterprises, while the second model can be applied to SMEs.

\section{The Choice of the Old-age Real Estate Mode Suitable for SMEs in China}

Firstly, in terms of development mode, SMEs should choose to cooperate with service agencies. SMEs have weak capital strength and risk tolerance, narrow financing channels and less market resources. Under these conditions, SMEs should choose the development mode of small investment, low risk level and short investment return period. SMEs only need to use most of the funds to build old-age housing to meet the needs of the elderly, so that they can not only become the main investor of old-age real estate, but also reduce the risk level by renting and selling houses for one-time recycling development costs. Although co-construction with the community will also reduce many costs, but SMEs do not have their own investment housing, and cost recovery period is too long. Through cooperation with service institutions, SMEs can enhance the professionalism of service supply, improve the quality of life of the elderly, and obtain important competitive advantages in the old-age real estate market at a lower cost.

Secondly, the mode of financing should be government-enterprise cooperation. SMEs entering the old-age real estate market should initially focus on gaining market share, then continue to improve core competitiveness to further improve product quality. Cooperating with the government can reduce the development cost of SMEs, especially the cost of land. It can also obtain policy support and administrative approval convenience. In addition, this mode can well reflect the profitability and welfare characteristics of the old-age real estate, can achieve social spillover benefits, and is conducive to corporate brand building and publicity. BOT and PPP are similar, but the difference lies in the length of sustainable profit, the degree of risk sharing and the capacity to assume responsibility. Therefore, the specific choice of model should be based on SMEs' own conditions and managers' ability to control investment risk.

Thirdly, the mode of operation should choose only construction but not operation. Because of the limitation of capital strength, SMEs can not effectively develop and operate the old-age service facilities and institutions in the later period. They need to recover the cost as soon as possible after the completion of the project. Although the industrial chain is very short and the long-term profit of SMEs is poor, they can avoid the risks brought by the latter operation. If SMEs want to improve the profitability to a certain extent, they can take the mode of combining rent and sale to rent some houses to the elderly who can not afford to buy houses. The mode can not only retain the value-added space of property rights, obtain sustained profits by collecting rents, but also meet the old-age needs of the elderly consumer groups.

\section{References}

[1] Edward Glaeser, Wei Huang, Yueran Ma, Andrei Shleifer. (2017). A Real Estate Boom with Chinese Characteristics. The Journal of Economic Perspectives, 31 (1): 93-116.

[2] J. Albert Cao, Ramin Keivani. (2018). Risks in the Commercial Real Estate Markets in China. Journal of Real Estate Literature, 16 (3): 363-383.

[3] Yongqiang Chu, Tien F. Sing. (2016). Inflation Hedging Characteristics of the Chinese Real Estate Market. The Journal of Real Estate Portfolio Management, 10 (2): 145-154.

[4] Graeme Newell, K. W. Chau, S. K. Wong, Keith McKinnell. (2015). Dynamics of the Direct and Indirect Real Estate Markets in China . The Journal of Real Estate Portfolio Management, 11 (3): 263-280.

[5] Andy Krause, Clifford A. Lipscomb (2016). The Data Preparation Process in Real Estate: Guidance and Review . Journal of Real Estate Practice and Education, 19 (1): 15-42.

[6] Liu Jinge (2016). Research on integration of massive information resources of real estate registration archives under the background of big data. Housing and Real Estate, 2016 (3): 116.

[7] K. W. Chau, K. G. McKinnell, S. K. Wong, Q. Wei, Graeme Newell. (2016). Impact of Corporate Governance Structures on the Relationship between Direct and Indirect Real Estate in China. The Journal of Real Estate Portfolio Management, 16 (1): 9-20.

[8] Jordi Gascón, Claudio Milano (2018). Tourism, Real Estate Development and Depeasantisation in Latin America. European Review of Latin American and Caribbean Studies, No. 105 (January-June 2018): 21-38. 
[9] Andy Krause (2016). Reproducible Research in Real Estate: A Review and an Example. Journal of Real Estate Practice and Education, 19 (1): 69-86.

[10] Jaime Bordenave, Dennis Stout (2016). Real Estate Analysis as a Tool for Program Evaluation. The Family Options Study, 19 (3): $475-486$.

[11] Rongda Chen, Diandian Cheng, Zhihong Lv, Yifeng Jin, Hejia $\mathrm{Du}$, Huiwen Chen (2016). Research on Investment and Financing Mode of Urban Infrastructure under Perspective of Cost Management. Quantitative Economics and Its Development, 30 (15): 4073-4099.

[12] George D. Cashman, David M. Harrison, Michael J. Seiler, Hainan Sheng (2016). Cross-Border Investment and Firm
Liquidity. The Journal of Real Estate Portfolio Management, 22 (2): 105-128.

[13] Martin Hoesli, Elias Oikarinen (2016). Are Public and Private Asset Returns and Risks the Same?: Evidence from Real Estate Data. The Journal of Real Estate Portfolio Management, 22 (2): 179-198.

[14] Xun Bian, Bennie D. Waller, Scott A. Wentland (2016). The Role of Transaction Costs in Impeding Market Exchange in Real Estate. Journal of Housing Research, 25 (2): 115-136.

[15] Frank Ametefe, Steven Devaney, Gianluca Marcato (2016). Liquidity: A Review of Dimensions, Causes, Measures, and Empirical Applications in Real Estate Markets. Journal of Real Estate Literature, 24 (1): 3-30. 